\title{
Power Factor Improvement of AC-DC Converter Based on Separately Excited DC Motor Using Passive Filter
}

\author{
Shazia Baloch', Mukhtiar Ahmed Mahar' ${ }^{2}$ Raza Haider $^{1}$, Shakeel Ahmed ${ }^{3}$ \\ ${ }^{1}$ Electrical Engineering Department, Balochistan University of Engineering and Technology, Khuzdar, Pakistan \\ ${ }^{2}$ Electrical Engineering Department, Mehran University of Engineering and Technology, Jamshoror, Pakistan \\ ${ }^{3}$ Civil Engineering Department, Balochistan University of Engineering and Technology, Khuzdar, Pakistan \\ Email: Shazia_balouch2002@yahoo.com,mukhtiar.mahar@faculty.muet.edu.pk, razahaider@buetk.edu.pk, \\ shakeel.baloch@buetk.edu.pk
}

Received 13 May 2016; accepted 11 July 2016; published 14 July 2016

Copyright (C) 2016 by authors and Scientific Research Publishing Inc.

This work is licensed under the Creative Commons Attribution International License (CC BY).

http://creativecommons.org/licenses/by/4.0/

(c) (i) Open Access

\begin{abstract}
In industries DC motor drives are very essential due to their high performance applications such as its reliability, ease of control, low cost and simplicity. And speed control of these motors is very easy due to power electronic AC-DC converters. These power electronic converters are with prominent low power factor and higher Total Harmonic Distortion (THD). These converters operate only for short time resulting non-sinusoidal waveform. This problem of harmonic distortion can be mitigated by reshaping the non-sinusoidal waveform to pure sine wave. Different wave shaping techniques have been developed by using different filters among which one is tuned passive filter. This paper proposed power factor improvement and harmonic mitigation of AC-DC converters based on separately excited DC motor using tuned passive filter. In this context experimental model is designed and results are analyzed by power quality analyzer.
\end{abstract}

\section{Keywords}

DC Motors, AC-DC Converters, Power Factor, Total Harmonic Distortion, Passive Filters

\section{Introduction}

DC (Direct Current) power supplies are important and extensively used in many electrical and electronics applications such as computers and telecommunication equipment. Because of the friendly technology electrical ve-

How to cite this paper: Baloch, S., Mahar, M.A., Haider, R. and Ahmed, S. (2016) Power Factor Improvement of AC-DC Converter Based on Separately Excited DC Motor Using Passive Filter. Open Journal of Energy Efficiency, 5, 71-77. 
hicle is rapidly increasing; thus DC power is becoming the heart of these systems [1] [2]. To achieve this DC recently a large number of different AC-DC converters have been developed and due to their low cost, high efficiency and fast switching actions these converters are used in DC motors on a large scale. DC motor drives have very essential industrial applications and are widely used because of its high performance. Speed control of DC motor is very easy by power electronic converters. And due to its favorable cost, reliability, simplicity and ease of applications DC motors have long been the backbone of industrial application [3]. AC-DC converters are playing a vital role in power electronics. In these power electronic converters, the AC supplies can be converted to DC. The non-linear natures of power electronic devices are of prominent harmonic distortion and low power factor which are of great concern [4]. It is also well known fact that AC-DC supplies suffer from two drawbacks i.e. current distortion and low power factor [5].

According to IEEE standards 519-1992, the harmonic distortions produced by power electronic devices should be under specific value that any individual harmonic should not be exceed more than $3 \%$ and total harmonic distortion should not be more than $5 \%$ [6].

Therefore, it is evidence that THD should not exceed more than $8 \%$ when load applied is varying and continuously changing and should be $5 \%$ when full-load is applied [7].

\section{AC-DC Converters}

A power electronic device which converts main AC voltage to DC voltage is called AC-DC converters. AC-DC converters are used in many applications such as in DC Motor speed control, Power supplies, Converters at the input end of DC transmission line, Portable hand tool drives and Solid state switch applications [8].

\section{Effects of AC-DC Converters}

- Voltage drops at the buses.

- Causes blown of fuses on power factor correction capacitors due to flow of high current and high voltage.

- Electromagnetic interference with the communication circuits.

- Heating of transformers, generators.

- Increase losses in the equipment connected to the utility such as transformers and motors.

\section{Harmonics}

The harmonics are defined as "a wave whose frequency is an integer multiple of the fundamental frequency" it can be odd harmonics or even harmonics. As power system is designed to operate with pure sinusoidal voltage and current with a constant frequency which is also known as fundamental frequency but by connecting the non-linear power electronics loads like diode and thyristors to the system causes excessive harmonics current which causes distortion of voltage and current. This in turns results power quality problems [9].

\section{Main Problem of Harmonics}

- Additional losses in supply generators and transformers.

- Neutral conductor overloading.

- Interference to communication.

- Over loading of power factor correcting capacitors supply voltage distortion.

- Error in energy meters.

- Malfunction of sensitive equipment.

- Reduced power factor to low values.

\section{Single Tuned Passive Filters}

By using passive elements like inductor, capacitor and resistor passive filters are designed so Passive filter consists of a certain combination of inductor capacitor and resistor as shown in Figure 1, which used to reduce the harmonic current [9] [10].

Many topologies for harmonic mitigation and active filter are used to control the harmonic. But power more than 1 MW passive filters are the best choice because some of the advantages such as low cost, simple design and high reliability. A single installation of passive filter can service many purposes i.e. reactive power compensation, power factor improvement, total harmonic distortion to acceptable limits. A well designed passive filter can be implemented in large sizes of MVAr ratings and provide almost maintenance free service [11]. 


\section{Research Objectives}

The objective of this research work is to develop an experimental model of single phase AC-DC converters based separately excited dc motor to analyze the harmonics caused by nonlinear nature of power electronics AC-DC converters and using single tuned passive filter to reduce harmonics according to IEEE standards 5191992 and power factor improvement.

\section{Research Methodology}

This research work is based on experimental setup and the methodology used for this research work is given as

- Development of experimental setup of dc motor with rectifier.

- Power factor and harmonic analysis of experimental models.

- Power factor improvement by using passive tuned filter.

\section{Experimental Setup}

Figure 2 shows the experimental setup of rectifier based separately excited dc motor it can be seen from the Figure 2 that the input supply is AC. To convert this AC into DC AC-DC converter is used. Power quality analyzer is used to measure the harmonic distortion and the power factor before and after installation of filter. Single tuned passive filter is used to improve the power factor and reduce the THD caused by AC-DC converter according to IEEE standard 519-1992. Figure 3 shows the developed experimental model of the research work.

\section{Harmonics and Power Factor before and after Installation of Filter At-Load}

Figure 4 and Figure 5 show the wave spectrum of AC-DC converter at-load without and with installation of

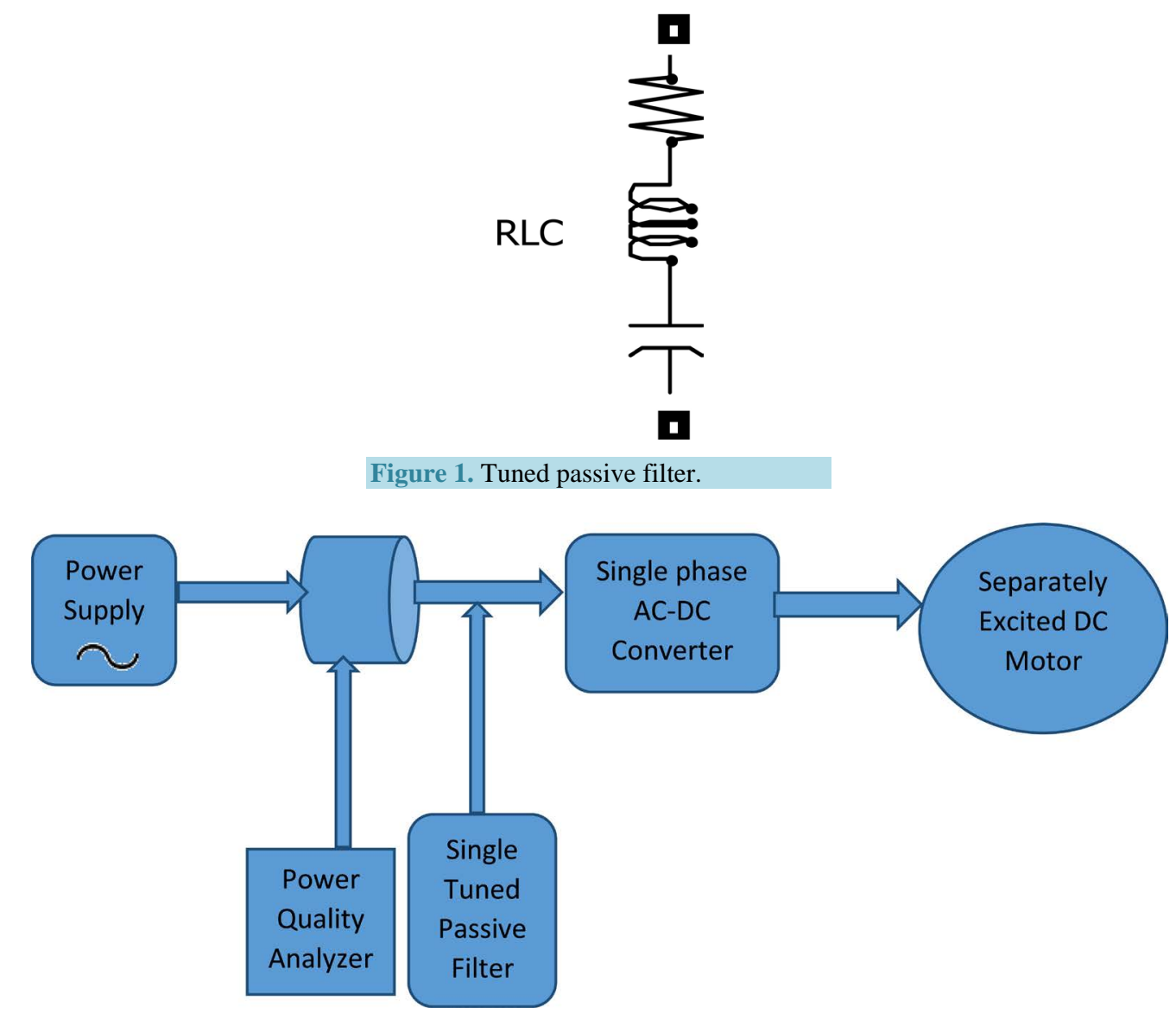

Figure 2. Experimental setup of rectifier based separately excited DC motor. 


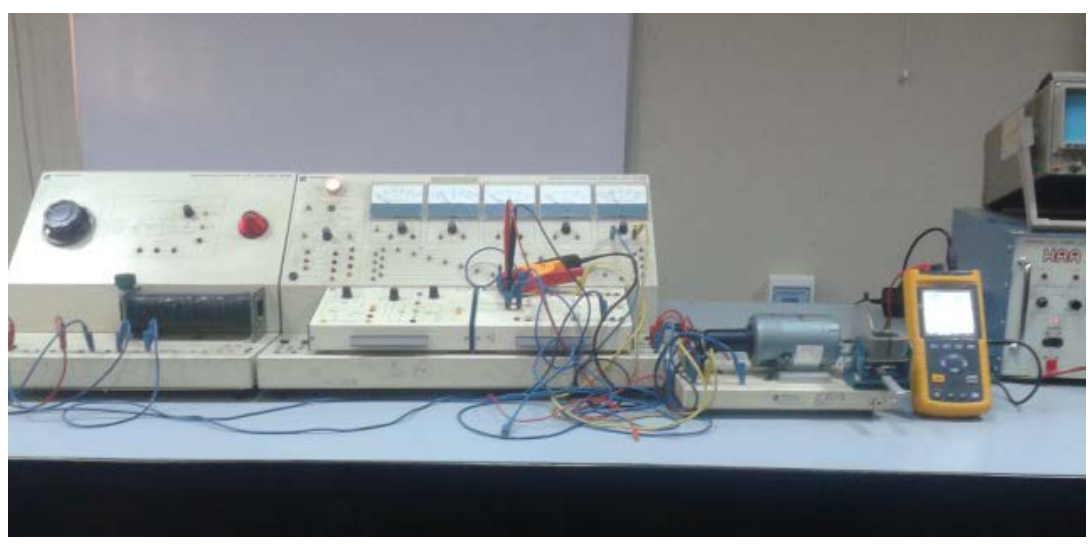

Figure 3. Experimental model of research work.

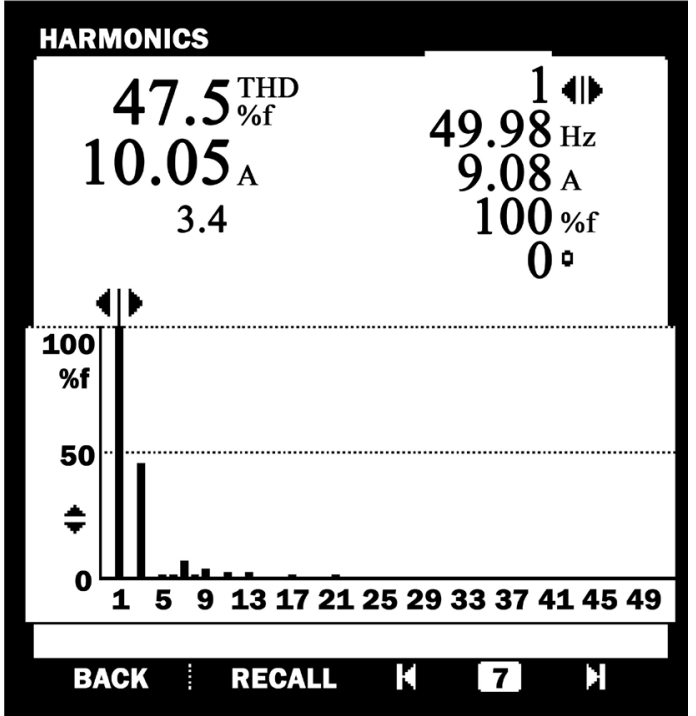

Figure 4. Wave spectrum of THD without filter.

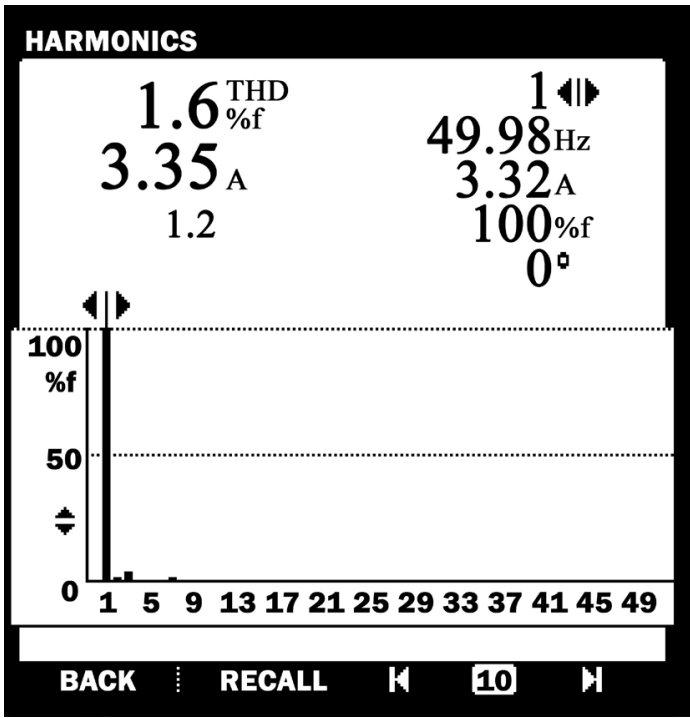

Figure 5. Wave spectrum of THD with filter. 
passive filter. It can be seen from the wave spectrum in Figure 4 that without installation of filter the THD measured is $47.5 \%$ which is very high to reduce the high THD passive filter is used and it can be seen from Figure 5 that after installation of passive filter the THD reduced from $45.5 \%$ to $1.6 \%$ at-load.

Similar to THD the power factor without filter is 0.67 as shown in Figure 6 which is very low but Figure 7 shows that after installing filter the low power factor has been improved from 0.67 to 0.99 .

Table 1 shows a comparison of power factor and THD with and without filter at-load. It can be seen from

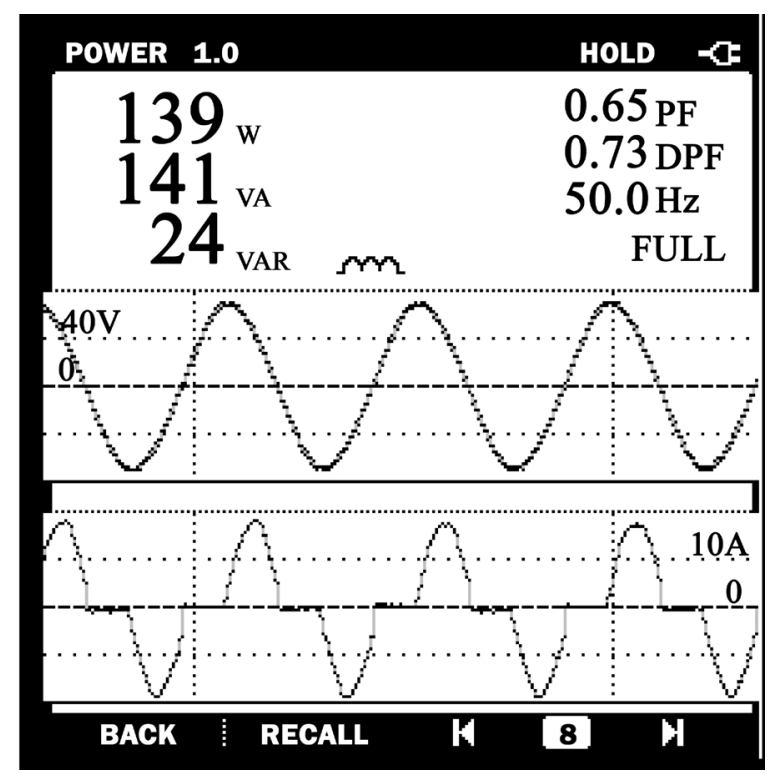

Figure 6. Power factor without filter.

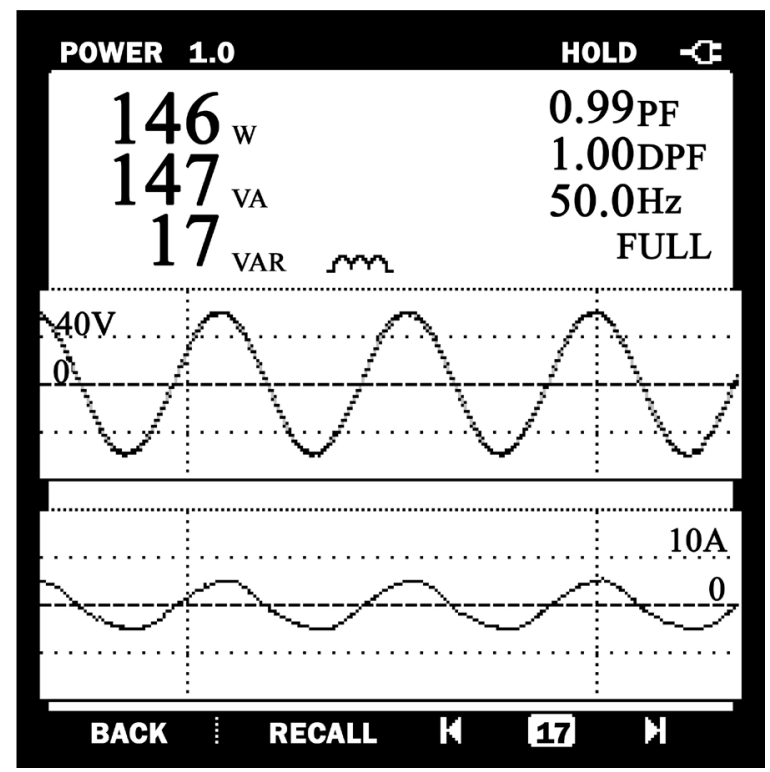

Figure 7. Power factor with filter.

Table 1. Power factor and total harmonic distortion with and without filter at-load.

\begin{tabular}{cccccc}
\multirow{2}{*}{ S.No } & \multirow{2}{*}{ Conditions } & \multicolumn{2}{c}{ Power Factor (PF) } & \multicolumn{2}{c}{ Total Harmonic Distortion (THDi) \% } \\
\cline { 3 - 6 } & & Without Filter & With Filter & Without Filter & With Filter \\
\hline \multirow{2}{*}{ 1. } & At load & 0.65 & 0.99 & 47.5 & 1.6 \\
\hline
\end{tabular}


the Table 1 that without filter the power factor at-load is very low i.e. 0.65 . To improve this power factor single tuned passive filter is used. After installation of filter the power factor has been improved up to 0.99 . Similarly without filter the total harmonic distortion was very high i.e. $47.5 \%$ but after installation filter it has been reduced to $1.6 \%$.

\section{Graphical Representation of PF and THD with and without Filter}

Figure 8 and Figure 9 show the comparison of power factor and THD by graphical representation. It can be

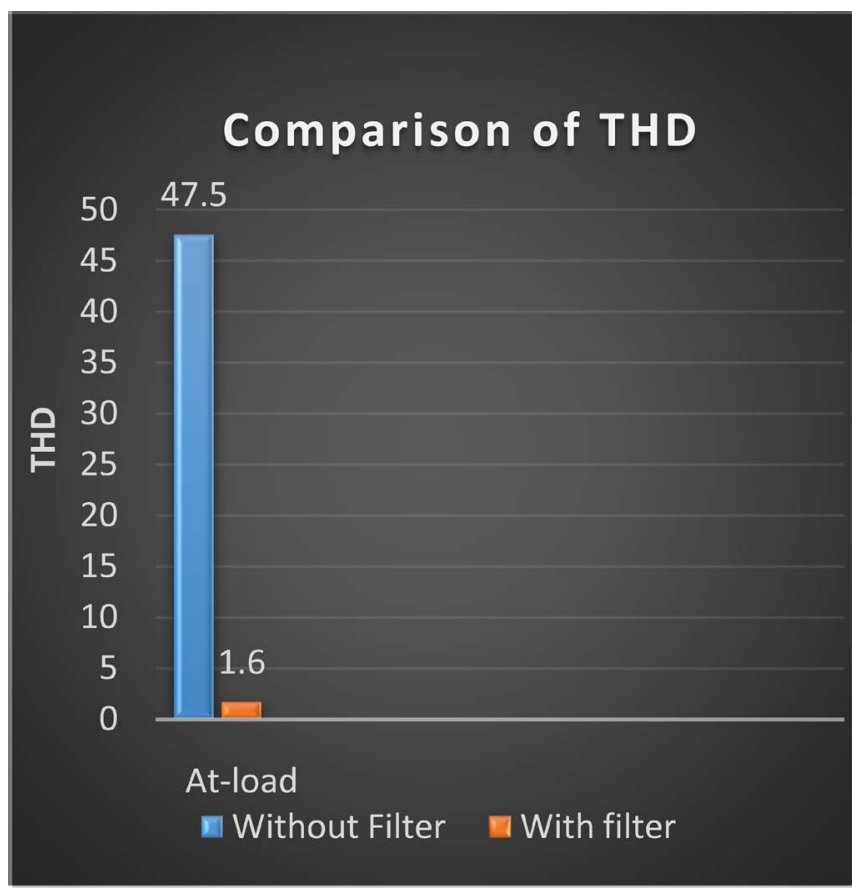

Figure 8. Graphical representation for the comparison of THD with and without filter.

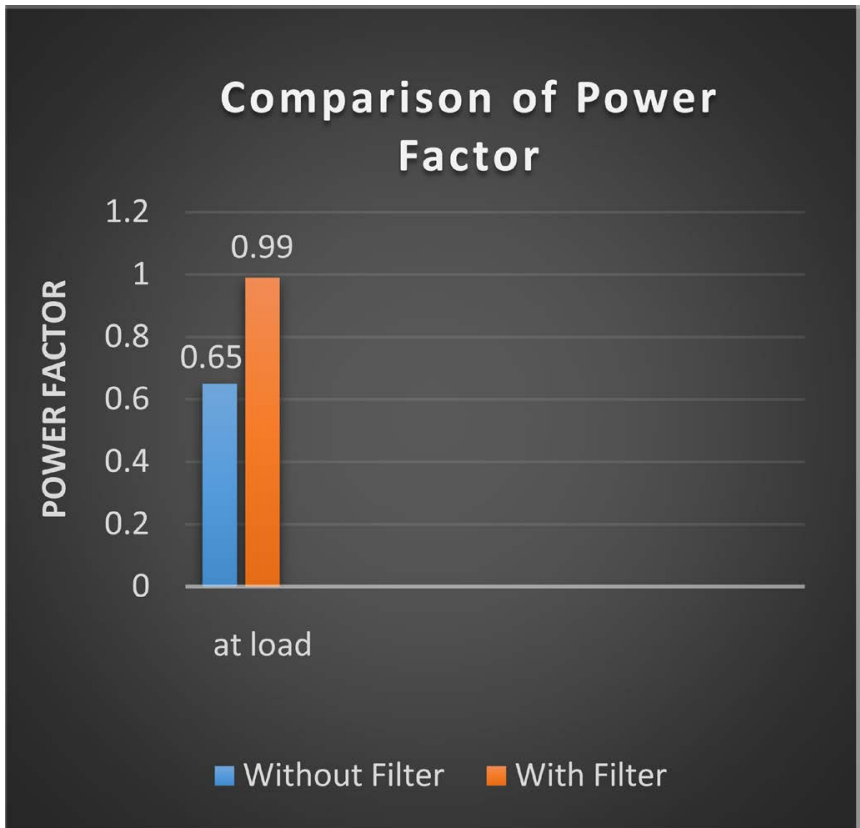

Figure 9. Graphical representation for the comparison of power factor with and without filter. 
seen from the comparison that without installation of filter the power factor is very low and total harmonic distortion is very high but after installation tuned passive filter the power factor improved to unity and total harmonic distortion reduced according to IEEE standard 519-1992.

\section{Conclusion}

In this research work power factor and total harmonic distortion of separately excited DC motor controlled with AC-DC converter has been analyzed at-load. The tuned passive filter is also designed in this research work. From the experimental results, it is concluded that the total harmonic distortion (at-load) has reduced within the range of IEEE Standards 519-1992. It has been seen that without filter the power factor of DC motor was very low i.e. 0.65 at-load and total harmonic distortion was very high $47.5 \%$. After development of single tuned filter, it is clear from experimental results that THD reduced within the range of IEEE standards 519-1992 and the power factor is improved near to unity at-load.

\section{Future Work/Suggestions}

As this research work was done on single phase converter using single tuned passive filter the same work can be extended on three phase AC-DC converter based DC drives. This research work can be extended to implement passive filters in field control methods of DC drives. Instead of single tuned passive filter we can also use parallel input resonant filter, series input resonant filter.

\section{References}

[1] Ismail Hossain, Md. and Alam, M.J. (2014) Cuk Topology Based Power Factor Correction and Output Voltage Regulation of Ac-Dc Converter. 2014 International Conference on Electrical Engineering and Information \& Communication Technology (ICEEICT), 10-12 April 2014, 1- 6. http://dx.doi.org/10.1109/ICEEICT.2014.6919126

[2] Gupta, R. and Ruchika, R. (2013) Thyristor Based DC Motor Control with Improved PF \& THD. International Journal on Electrical Engineering and Informatics, 5, 519-536. http://dx.doi.org/10.15676/ijeei.2013.5.4.10

[3] P.karpagavalli, P. and Jeyakumar, A.E. (2014) Power Factor Improvement in Single Phase dc Motor Drive Using Double Sided Pwm Switching. Journal of Theoretical and Applied Information Technology, 69, 232.

[4] Lenine, D., Sai Babu, Ch. and Surya Kumari, J. (2010) A Static Improvement of Predictive Control for Single Phase Voltage Fed Power Factor Correction Converters. 2010 International Conference on Advances in Recent Technologies in Communication and Computing (ARTCom), Kottayam, 16-17 October 2010, 116-120. http://dx.doi.org/10.1109/ARTCom.2010.16

[5] Ahmed, M.M.R., Putrus, G.A. and Shokralla, S.S. (2005) A New Approach for Speed Control of A.D.C. Motor Fed from AC to DC Sepic Converter. 18th International Conference and Exhibition on Electricity Distribution, Turin, 6-9 June 2005, 1-5. http://dx.doi.org/10.1049/cp:20051219

[6] Pyakuryal, S. and Matin, M. (2013) Harmonic Analysis for a 6-Pulse Rectifier. IOSR Journal of Engineering, 3, 57-60. http://dx.doi.org/10.9790/3021-03325760

[7] Memon, Z.A., Uqaili, M.A. and Soomro, M.A. (2011) Experimental Analysis of Harmonic Mitigation Effects on Three Phase Six Pulse Converter by Using Shunt Passive Filter. Mehran University Research Journal of Engineering \& Technology, 30, 653-656.

[8] Rashid, M. (2011) Power Electronics: Circuits, Devices, and Applications. 3rd Edition, Prentice Hall, New Jersey.

[9] Soomro, D.M. and Almelian, M.M. (2015) Optimal Design of a Single Tuned Passive Filter to Mitigate Harmonics in Power Frequency. ARPN Journal of Engineering and Applied Sciences, 10, 9009-9014.

[10] Zobaa, A.F., Abdel Aziz, M.M. and Abdel Aleem, S.H.E. (2010) Comparison of Shunt-Passive and Series-Passive Filters for DC Drive Loads. Electric Power Components and Systems, 38, 275-291. http://dx.doi.org/10.1080/15325000903273262

[11] Das, J.C. (2003) Passive Filters-Potentialities and Limitations. 2003 Conference Record of the 2003 Annual Pulp and Paper Industry Technical Conference, Charleston, 16-20 June 2003, 187-197. http://dx.doi.org/10.1109/PAPCON.2003.1216916 


\section{Submit or recommend next manuscript to SCIRP and we will provide best service for you:}

Accepting pre-submission inquiries through Email, Facebook, LinkedIn, Twitter, etc.

A wide selection of journals (inclusive of 9 subjects, more than 200 journals)

Providing 24-hour high-quality service

User-friendly online submission system

Fair and swift peer-review system

Efficient typesetting and proofreading procedure

Display of the result of downloads and visits, as well as the number of cited articles

Maximum dissemination of your research work

Submit your manuscript at: http://papersubmission.scirp.org/ 